\section{PHYSIOLOGY}

\section{Why sunburn stings}

A membrane protein in skin cells transmits signals that trigger pain and tissue damage that put the 'burn' into sunburn.

Wolfgang Liedtke of Duke University in Durham, North Carolina, and his colleagues switched off production of a cellular ion channel called TRPV4 in the epidermis of genetically engineered mice. They exposed the mice to ultraviolet (UV) radiation, which causes sunburn.

Compared with UV-exposed mice that had normal TRPV4 production, the engineered mice had less damage on their hind-paw pads (which resemble human skin). Their paws were also less sensitive to heat or to being poked with fine wires - signs that the engineered mice experienced less pain. Furthermore, three human patients with sunburn had higher expression of TRPV4 in their epidermis than three unburned controls.

Proc. Natl Acad. Sci. USA http://dx.doi.org/ 10.1073/ pnas.1312933110 (2013)

\section{TROPICAL DISEASE}

\section{Malaria vaccine protective at last}

A vaccine made of a purified, weakened form of a malaria parasite gave $100 \%$ protection in a small clinical trial.

Of six people who were given five intravenous doses of the live-attenuated vaccine and then bitten by infectious mosquitoes, none developed malaria. Five out of six unvaccinated people did get the disease, as did three out of nine patients who received lower doses of vaccine. These levels of protection, reported by Robert Seder at the National Institutes of Health in Bethesda,

Maryland, and his colleagues, surpass any previously achieved for a malaria vaccine. The vaccine will now be tested in larger field trials in Africa, which will determine how long protection lasts and whether it works against other strains of the malaria parasite.

Science http://dx.doi.org/ $10.1126 /$ science. 1241800 (2013)

For a longer story on this research, see go.nature.com/mae5tu

\section{PALAEONTOLOGY}

\section{Toothy patch in fossil fish}

Jawless fish that swam the seas some 400 million years ago may have relied on the same mechanism to repair bone damage as modern mammals do to mend their teeth.

A team led by Zerina Johanson at the Natural History Museum in London analysed fossils of the large fish Psammolepis from rock formations in Estonia and Latvia. Psammolepis are covered by bony shields ornamented with a thin layer of dentine, the same tissue that makes up teeth. One specimen had a damaged armour plate, possibly from a predator attack. The researchers were surprised to find that the bony plate was plugged not with bone, but with dentine.

Specialized stem cells speed the regrowth of dentine in extant mammals such as humans and mice, and the researchers suggest that a similar mechanism existed in this toothless fish to repair its bony armour.

Biol. Lett. http://dx.doi.org/ 10.1098/rsbl.2013.0144 (2013)

\section{CANCER BIOLOGY}

\section{Genome mix-ups monitored}

Cancer cells often contain translocation mutations, in which parts of the genome are swapped between chromosomes. For the first time, scientists have been able to watch these accidents as they happen in living cells.

Researchers led by Tom

Misteli at the National

Cancer Institute in Bethesda,

Maryland, coupled

COMMUNITY CHOICE

The most viewed papers in science

\title{
Young female birds get the worm
}

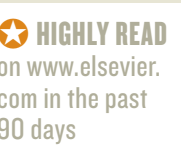

Birds' ability to learn from watching their peers varies with age, sex and social rank. In a study led by Lucy Aplin at the University of Oxford, UK, wild-caught blue tits (Cyanistes caeruleus; famous for learning to pierce foil caps on milk bottles delivered to British homes to get the cream) were placed in an aviary with a covered tray containing waxworms, the blue tit's favourite snack. Eight experimental groups totalling 56 birds could observe 'demonstrator' birds that had been trained to get worms by either flipping up or piercing the covers. About half of these birds learned to get the worms, but when 32 other birds were given the tray in the absence of demonstrators, none of them learned the skill. Juvenile females were almost twice as likely to learn the task as other blue tits, and dominant males less likely. Anim. Behav. 85, 1225-1232 (2013)

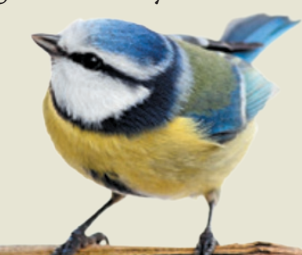

ultra-high-throughput techniques for time-lapse imaging with a system for 'snapping' DNA strands in chromosomes, and watched what happened to DNA fragments in cultured cells. On rare occasions, the breaks occurred in separate chromosomes and the broken ends attached to the wrong partners. These translocations formed within hours of a break and were guided by the cell's repair machinery. The work will allow further study of how and when chromosomal mixups occur.

Science 341, 660-664 (2013)

\section{Sneaky breeders make sons}

Altruistic worker bees usually abstain from reproduction - unless they have a shot at making a royal baby.

Michael Holmes at the University of Sydney in Australia and his colleagues monitored the fertility and breeding habits of seven colonies of Western honeybees (Apis mellifera). It was thought that workers (who are all female) refrain from breeding and instead raise the queen's brood, which is better for the colony's overall success. But the researchers found that overall, $4.2 \%$ of males (drones) are produced by workers, a level 40 times greater than that typically reported. Furthermore, just before virgin queens set out to establish their own hives, a worker baby boom occurs and the number of workerproduced drones peaks at more than $6 \%$.

The authors speculate that workers may risk breaking rank for the chance of producing a new queen's future mate.

Mol. Ecol. 22, 4298-4306 (2013)

\section{$\rightarrow$ NATURE.COM}

For the latest research published by Naturevisit:

www.nature.com/latestresearch 